rates could be offered to the vast number of people in developing countries who seek knowledge.

SING LEE

Department of Psychiatry, Senior lecturer

Chinese University of $H$ Hong

11/F, Prince of Wales Hospital,

Shatin,

Hong Kong

1 Smith R. Chinese medical journals: getting in touch. $B M f$ 1994;309:74. (9 July.)

2 Lee S. The vicissitudes of neurasthenia in Chinese societies: where will it go from the ICD-10? Transcultural Psychiatric Research Review (in press).

\section{The placebo effect}

\section{Wrong patients receive treatment}

EDrToR,-Vernon M S Oh leaves us with a medica dilemma: on the one hand he tells us that we "should consider giving a placebo to appropriate patients," but, earlier in the review, he tells us that "selecting the patients most likely to benefit from placebo is difficult." In practice, doctors tend to give placebos to the least appropriate patients. These include neurotic patients, who are least likely to respond ${ }^{2}$; demanding patients who have an investment in not responding; and chronically ill patients who suffer from what psychologists have called placebo sag. Most placebos are probably given unwittingly by the doctor, ${ }^{3}$ and this folie à deux makes the placebo particularly effective. In this context, and with many active treatments, the placebo effect may be at its greatest but goes unrecognised.

Placebos' effectiveness is largely a function of the attitudes and skills of the doctor and his or her therapeutic authority and relationship with the patient. These factors are also important in consultations in which active drugs or no drugs are given. Indeed, a therapeutic consultation can be equally as effective as one in which either a placebo or symptomatic medication is given. ${ }^{4}$ Maximising the placebo effect should therefore be the aim of every consultation, and learning the necessary skills should, as Robert Buckman and George Lewith suggest, ${ }^{5}$ be part of the medical curriculum.

Neither drug companies nor medical reputations have much to gain from the placebo effect. This may partly explain why medical attitudes to it and, indeed, to doctors' role as healers have failed to keep up with recent research in psychology and psychoneuroimmunology. This is why patients are increasingly turning to complementary therapists. The paradox is that the success of modern medicine has given doctors, rather than other therapists, a much more powerful role in using the placebo effect. We have the way, it seems, but not the will.

MICHAEL DIXON

College Surgery,

Cullompton,

Devon EX15 1TG

1 Oh VMS. The placebo effect: can we use it better? $B M 9$ 1994;309:69-70. (9 July.)

2 Rosenberg NK, Mellergard M, Rosenberg R, Beck P, Ottosson

JO. Characteristics of panic disorder patients responding to placebo. Acta Psychiatr Scand Suppl 1991;365:33-8.

3 Dunlop DM, Henderson TL, Inch RS. Survey of 17301 precriptions of form EC10. BMf 1952;i:292-5.

Thomas KB. The consultation and the therapeutic illusion. $B M$ 1978;i:1327-8.

5 Buckman R, Lewith G. What does homoeopathy do-and how? BMf 1994;309:103-6. (9 July.)

\section{May be harmful in non-organic disorders}

EdrToR,-Vernon M S Oh's editorial on the placebo effect does not draw attention to the dangers of placebo treatment. ${ }^{1}$ It is often said with regard to placebo treatment that at least if it does not work it will do no harm, but this is not so.
Patients often tend to equate the severity of their illness with the amount of treatment they receive. Any form of treatment, whether it be a placebo or a pharmacologically active drug, can reinforce a patient's belief that he or she is suffering from a disease, which in functional disorders may be positively harmful.

I believe that placebo treatment, if it is to be used at all, should be reserved for disorders in which organic disease has been firmly diagnosed. If placebo treatment has been initiated in nonorganic disorders and does not work, great pressure is put on the doctor to introduce a more active treatment and a dangerous crescendo of treatment can result. A typical case often seen in orthopaedic practice is of a young girl presenting with a painful wrist but without physical signs, who is referred for placebo physiotherapy. When this does not work a plaster cast is applied, then steroid injections may be given; these may be followed by a surgical exploration for some presumed pathology, with negative results, and finally a despairing referral to a pain clinic. No doubt similar cases can be identified in other specialties. Overtreatment of functional or trivial disorders may inflate them into major problems.

JCHALMERS

Murrayfield Hospital,
Edinburgh EH12 6UD

1 Oh VMS. The placebo effect: can we use it better? $B M F$ 1994;308:69-70. (9 July.)

\section{Use outside trials may be unethical}

EDITOR,-Vernon Oh's editorial "The placebo effect: can we use it better?" might more usefully have been entitled "The placebo effect: can we use it at all, at least outside clinical trials?"' In randomised trials, where informed consent, collusion between medical and paramedical staff, and coded interventions are the norm, use of a placebo is widespread. In the remainder of clinical practice formidable practical and ethical problems remain.

Many doctors have experienced nurses' reluctance to give pharmacologically inert substances. Certainly, placebo interventions cause serious ethical dilemmas for nurses, ${ }^{2}$ who increasingly see their roles as including that of patient advocate, with honesty being paramount in this relationship. The principle of informed consent is embodied in the patient's charter, which states that every patient has the right "to be given a clear explanation of any treatment proposed, including any risks and any alternatives." ${ }^{3}$ Kendrick concluded that "it is extremely difficult to think of a situation where lying can ever be acceptable . . . between a nurse and her ... patient." The trend towards more open, less paternalistic delivery of health care, including access by patients to their files, drug charts, and product information, presents practical barriers to the use of placebos. Placebo interventions entail active deceit, including collusion with other staff.

Dangers are inherent in such deceit. Its inevitable occasional discovery leads to reduced efficacy and to loss of faith in the practitioner and in the medical profession. ${ }^{3}$ Patients, some in desperate need of help, may feel angry and betrayed and believe that they have been labelled as mad or malingering or that their complaints are being regarded as not real. Such a risk of alienation is not confined to placebo interventions. It exists in conditions such as the chronic fatigue syndrome, repetitive strain injury, and functional abdominal pain, in which treatment strategies that acknowledge an appreciable psychological aetiology are used. Unfortunately, the media and the general public tend to have a simplistic, dualist approach to the mindbody problem.

In practice, use of placebo interventions may be limited to randomised trials in the context of informed consent. This should not distract us from the power of the placebo effect, pervasive in medical practice, which is engendered by any successful doctor-patient interaction, whether taking a history or making a surgical incision.

JONATHAN R PRICE Senior house officer

Nuffield Orthopaedic Centre,

Oxford OX3 7LD

1 Oh VMS. The placebo effect: can we use it better? $B M 9$ 1994;309:69-70. (9 July.)

2 Elander G. Ethical conflicts in placebo treatment $f$ Adv Nurs 1991;16:947-51.

3 Department of Health. The patient's charter. London: $\mathrm{DoH}$ 1993.

4 Kendrick K. Should nurses always tell the truth? Honesty versu deception in healthcare. Professional Nurse 1994;9:674-7.

5 Brody $\mathrm{H}$. The lie that heals: the ethics of giving placebos. Ann Intern Med 1982;97:112-8.

\section{Involves deception}

EdrTor,-Vernon M S Oh glosses over ethical questions about the use of placebos and ignores problems in defining the placebo concept. Because he uses Shapiro's definition of placebo, which is what Grunbaum calls an intentional placebo, ${ }^{3}$ he does not make a clear differentiation from the inadvertent placebo. Placebos are not always given wittingly, as $\mathrm{Oh}$ acknowledges. $\mathrm{He}$ is prepared to accept that homoeopathy or even some conventional treatments may work through the placebo effect and that patients with cancer gain in optimism because of complementary treatments. Yet exhorting doctors to use placebos in certain circumstances in appropriate patients implies that doctors should deliberately use simulated effects. $\mathrm{Oh}$ is apparently encouraging doctors to deceive their patients.

The action of placebos emphasises the power of suggestion. A history of Freudian psychoanalysis is the rejection of the suggestion of hypnosis for the transference of the analysis. Frank postulated that all treatments comprised a specific element and a non-specific placebo element aimed at counteracting demoralisation. ${ }^{4}$ Indeed, Frank suggested that the success of the many forms of psychotherapy was due to a placebo effect rather than the distinctive features claimed by the different therapists. Like Oh, Frank encouraged us not to minimise the value of the placebo effect. Frank, however, proposed taking advantage of the dynamic relationship between doctor and patient, whereas Oh suggests that doctors should give dummy drugs or other phoney interventions.

Therapeutics generally does not pay adequate attention to psychological and social variables. Classic papers such as Beecher's have a sobering implication. ${ }^{5}$ The recognised surgical procedure of ligating the internal mammary artery for angina was shown to be ineffective by well controlled studies that used sham bilateral skin incision as a control. The ethics of these studies has been questioned because of the deception entailed in the sham surgery. The advantages to patients who receive inadvertent placebos may, however, justify more studies of this sort, instead of subjects being asked to join in the deception of a double blind trial through informed consent, as is more usual in current research. Placebos could be used better in research and must not be used to exploit patients.

D B DOUBLE

South East Sheffield Mental Health Services, Consultant psychiatrist Sheffield S12 4QN

1 Oh VMS. The placebo effect: can we use it better? $B M \mathcal{J}$ 1994;309:69-70. (9 July.)

2 Shapiro AK. A historic and heuristic definition of the placebo. Psychiatry 1964;27:52-8.

Grunbaum $A$. The placebo concept in medicine and psychiatry. Psychol Med 1986;16:19-38.

4 Frank JD. Persuasion and healing. Revised ed. Baltimore: John Hopkins University Press, 1983.

5 Beecher HK. Surgery as placebo. FAMA 1961;176:1102-7. 